\title{
Improving the efficiency of electric network equipment operational service
}

\author{
Elena Rychagova $^{1 *}$ and Vladimir M. Levin ${ }^{1}$ \\ ${ }^{1}$ Novosibirsk State Technical University, Karl Marks str. 20, Novosibirsk, Russia
}

\begin{abstract}
Maintenance and repair (M\&R) of electric network equipment is one of the crucial methods for reliable power supplying. For implementing the condition based maintenance strategy is necessary to solve a number of problems, including prioritizing of preventive measures order and determining optimal time of their periodic. This paper points out two specific aspects: 1) development of an adequate reliability simulation model to optimize the operational factors of electric network equipment; 2) advantages of the proposed M\&R optimization methodology in the operational process of real distribution system. Developed probabilistic mathematical model of M\&R allows determining criteria for obtaining the optimal solution according to the results of numerical calculations procedures. Described mathematical model is based on the theory of controlled Markov processes. This mathematical method allows describing "ageing" systems. The main advantages of the model are the possibility of considering all random processes for described type of equipment and obtaining the analytical solutions for basic reliability and economical indexes. Based on this, the criterions and strategy for choosing an optimal time intervals of M\&R procedures have been formed. Improving the efficiency of $M \& R$ of electrical equipment is considered on a real distribution network.
\end{abstract}

\section{Introduction}

A problem of distribution power networks $6-35 \mathrm{kV}$ reliability is relevant and attracts special attention of scientists and engineers. There are a number of objective reasons for this. Firstly, the lower observing of this voltage class distribution networks, periodic diagnostic, increased wear and tear of power equipment (PE) and limited recourses for its modernization are leading to improving the methods and decision-making criterions for the effective management of power equipment maintenance and repair. Secondly, an implementation of the Smart Grid is attended by adoption of advanced technologies and means of data acquisition, processing and transmission connected to the local distributed generation systems (including renewable sources) and to the power storage systems. Described reasons lead to create new correct strategy of scheduling the restoring power equipment reliability procedures and get the optimal technical and management solutions.

The research objective is to develop the methodology of M\&R optimization and obtain mathematical models that are correct to the studied processes of power equipment operation.

\section{Probabilistic models}

Operation of electrical distribution systems is carried out under the influence of a significant number of random factors and incomplete initial information about power system reliability [11]. Described features of "ageing" systems operation should be compensated by choosing the correct methodology of processes modeling that includes changing of the influencing factors. According to the previous researching [1]-[4], [9] the widely used and the most approached methodology is controllable Markov (Semi-Markov) random processes methodology.

Equation (1) is used for describing "ageing" systems evolution with increasing function of failure frequency; where $\omega_{0}$ - initial failure frequency, $b$ - coefficient indicating the rate of equipment aging:

$$
\omega(t)=\omega_{0}+b \cdot t
$$

\subsection{Failure model, including the factor of ageing}

Failure models of power systems are special class of models designed to describe changes in the parameters of random flow of events and calculate its probabilistic characteristics [12], [13]. However, due to the varios reasons of systems failures it is quiete complicated to obtain such models. The same problem applies to power equipment of distribution systems. There are random and deterioration failures of power equipment. Random (sudden) failures are mainly associated with accidental external influences on power equipment operation (thunderstorm insulation overlap, destruction of overhead line support towers, etc.) and do not depend on

rychagova elena@mail.ru 
its technical condition. The deterioration failures are depending on the aging processes, deterioration processes of materials and structural elements properties of power equipment (PE). The fundamental difference in the rate of occurring random and deterioration failures of $\mathrm{PE}$ is considered in the model [14], where the property of unsteadiness of random events flows is used. The unsteady event flow is based on the assumption [15] that the probability of the time interval between failures is not constant, and depends on the initial point $t_{0}$ on the time axis. In this way, the failure model includes equipment service life and its special degradation characteristics.

The probability of failure the i-th non-redundant unit of power system is determined by equation (2):

$$
Q_{i}(t)=1-\exp \left[-\omega_{0 i} \Delta t-b_{i}\left(2 t_{0 i} \cdot \Delta t+\Delta t^{2}\right) / 2\right]
$$

$\Delta t$ - considered operational time, $t_{0 i}$ - equipment service life (year). In the presence of structural redundancy in the i-th section of the network (several overhead lines, several parallel transformers at the substation), the failure probability of the redundant unit of PE is calculated by the equation (3):

$$
Q_{i}^{r}(t)=\prod_{j=1}^{n} Q_{i}^{j}(t)
$$

$Q_{i}^{j}(t)$-probability of failure the j-th unit of PE of i-th group, $\mathrm{n}-\mathrm{a}$ number of parallel units included in the group of PE.

\subsection{M\&R Model}

The purpose of maintenance is to extend equipment lifetime, or at least the mean time to the next failure whose repair may be costly. Furthermore, it is expected that effective maintenance policies can reduce the frequency of service interruptions [1]. Maintenance is divided into preventive and corrective measures. This classification describes the difference in application. For example, the purpose of preventive maintenance is to reduce the power equipment failure probability. This type of maintenance is performed before the failure of PE. Corrective maintenance (repair), the purpose of which is restoring of operational condition, is performed after the detection of a fault in it.

For describing the real-managed random process of electric network equipment operation is used the homogeneous semi-Markov models with continuous time [4]-[6]. The unified probabilistic model of condition based maintenance (CBM) has been developed. The developed model of $M \& R$ is represented as directed graph (Fig.1). The graph's nodes indicate the probable state of the system during the operation period, and the arcs - transitions from one state to another. For the graph's description is used the system of algebraic equations (4).

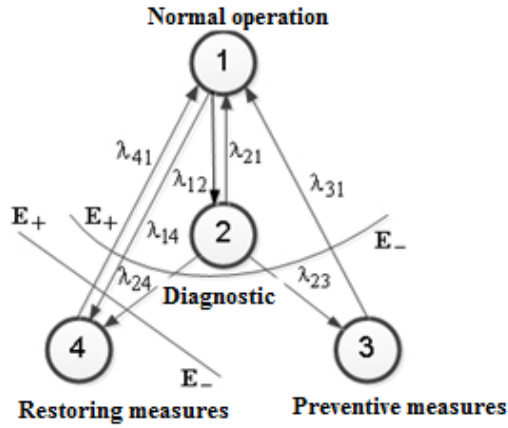

Fig. 1. Graph of power equipment state

$\sum_{i=1}^{4} P_{i}=1$

$$
\begin{aligned}
& \lambda_{12} \cdot P_{1}-\left(\lambda_{21}+\lambda_{23}+\lambda_{24}\right) \cdot P_{2}=0 \\
& \lambda_{23} \cdot P_{2}-\lambda_{31} \cdot P_{3}=0 \\
& \lambda_{14} \cdot P_{1}-\lambda_{24} \cdot P_{2}-\lambda_{41} \cdot P_{4}=0
\end{aligned}
$$

where $p_{i}$ - stationary probabilities of $\mathrm{PE}$ in $\mathrm{i}$-th condition $(\mathrm{i}=1-4) ; \lambda_{\mathrm{ij}}$ - intensities of transitions from $\mathrm{i}$-th to $\mathrm{j}$-th condition. Developed model allows considering the whole set of random event flows for a particular type of PE. Any electrical network component during operation is able to pass with period [tau] from the correct state 1 to diagnostic state 2 by duration $T_{\mathrm{d}}$. According to the diagnostics results with a probability $q_{1}$ the component passes to operable state 1 ; with probability $q_{2}$ can pass to preventive maintenance state 3 for correcting the developing defect; with probability $q_{3}$ can pass to emergency repair (replacement) state 4 , for correcting the consequences of failure and resource recovery. Here: $q_{1}$ the probability of failure non-occurring between successive sessions of diagnostic during the time [tau]; $q_{2}$ - the probability of failure occurring between successive sessions of diagnostic during the time [tau], but it doesn't develop to the hard fault, $q_{3}$ - the probability of failure occurring and developing to hard fault condition between successive sessions of diagnostic during the time [tau]. Between ordinary sessions of diagnosis with the rate $\omega(t)$ is possible hidden failure of component. It should be detected and corrected during emergency repairs (1-4 transition).

\subsection{Reliability and Economic indexes}

Numerical solutions of system of equations (4) allow calculating failure-free probability changes during operational time:

$$
p_{1}(t)=\left[1+t^{-1}\left(T_{\mathrm{d}}+q_{2} T_{\mathrm{pr}}+q_{3} T_{\mathrm{em}}\right)+\omega(\mathrm{t}) T_{\mathrm{em}}\right]^{-1}
$$

Also is possible to obtain equations for dependences which form the criteria for choosing optimization strategies. An analytical solution as a function of the average frequency of equipment failures has been obtained:

$$
\bar{w}_{\text {fail }}(\mathrm{t})=\left(T_{\mathrm{em}}+\frac{A+B \cdot t}{C+D \cdot t}\right)^{-1}
$$

where the coefficients $A(\mathrm{~h}), B(\mathrm{pu}), C(\mathrm{pu}), D\left(\mathrm{year}^{-1}\right)$ 
calculated from the previously listed operating data. According to the equation (6) is possible to calculate the total operational costs during considerable interval of operational time $\Delta T$ (year) and including the specific features of $\mathrm{PE}$ and costs of repair procedures:

$$
C_{S}(t)=\sum_{t=0}^{\Delta T}\left[\left(\frac{c_{r}}{c_{p}}\right) \bar{w}_{f a i l}(t)+\bar{w}_{\text {plan }}^{\prime}(t)\right] c_{p} t
$$

$\bar{w}_{\text {plan }}^{\prime}(\mathrm{t})$ (year-1) - average frequency of planned (maintenance) outages of PE, $c_{\mathrm{r}}$ and $c_{\mathrm{p}}$, (\$) - average cost of recovery and prevention of particular type of equipment.

Unscheduled disconnections of the distribution network elements lead to power supply interruptions, technological and other losses $(\Delta \bar{\Pi})$, measured by the value of the mathematical expectation of damage $D$. Thus, damage is a random variable that quantifies the risk of power equipment failures. For calculation the mathematical expectation of damage from technological losses of oil production in case of failure of the i-th element of the network and power supply interruptions in [4], the dependence (8) has been developed:

$D(t)=\xi_{0} \sum_{\mathrm{i}=1}^{\mathrm{n}} \sum_{\mathrm{t}=0}^{\Delta \mathrm{T}}\left[\Delta \bar{\Pi}_{\mathrm{i}}\left(1-\exp \left(-\lambda_{\Delta \Pi_{\mathrm{i}}} \Delta \bar{\Pi}_{\mathrm{i}}\right)\right) \bar{w}_{\text {fail }}(\mathrm{t})\right] t$

where : $\Delta \bar{\Pi}_{i}$ (ton/outage), $\lambda_{\Delta \Pi_{i}}$ (outage/ton) - average amount and frequency of technological losses in case of failure of the i-th element of the network, $\xi_{0}$ (Rub/ton) unit cost of losses. Combination of total operational costs including risk of failures allows obtaining the following equation (9):

$$
C_{\mathrm{R}}(t)=C_{\mathrm{S}}(t)+D(t)
$$

\subsection{Decision-making criteria of M\&R management}

Management performance targets - decision-making criteria are directly related to the M\&R strategy of power equipment adopted for implementation and the features of considered problem. There are two key management problems for implementation condition based M\&R strategy: 1) Order of measures priority; 2) Optimization of maintenance and repair frequency of electric network similar elements. For solving the first problem is necessary to list similar type of power equipment, to calculate their unique technical and economic characteristics, to rank each listed element according to the decreasing order of efficiency index value. It's possible to do base on the one of the following requirements: $Q_{i}^{r}(t) \rightarrow \min ; \bar{w}_{\text {fail }}(\mathrm{t}) \rightarrow \min ; C_{\mathrm{R}}(\mathrm{t}) \rightarrow$ min.

According to the researching results, the correct order of M\&R priority on the interval of operation $\Delta t$ could be obtained using the criterion $R_{\mathrm{cr}} \rightarrow \min$, where

$$
R_{\mathrm{cr}}=\frac{Q_{i}^{r} \cdot D_{i}}{\sum_{i=1}^{n} Q_{i}^{r} \cdot D_{i}}
$$

$R_{\text {cr }}$ - criticality rank of power equipment failures, which includes the probability of unscheduled and degradation failures and the severity of the undesirable consequences caused by failures.

The second problem solution requires an iterative process of solving the algebraic equations system (4) with the calculation of reliability and economic indexes (5) - (9) and determining the values of $T_{\text {opt }}$ corresponding to (11).

$$
\frac{d p_{1}(t)}{d t}=0, \quad \frac{d \bar{w}_{\text {fail }}(t)}{d t}=0, \quad \frac{d C_{\mathrm{R}}(t)}{d t}=0
$$

\section{Algorithm of optimization calculations}

Algorithm of calculations is the key part of decisionmaking procedures for $\mathrm{M} \& \mathrm{R}$ management of power equipment. An algorithm development for carrying out a variant optimization calculations requires using of scripts in accordance with the target indicators of efficiency of M\&R management. Also, the consistency of initial information and the areas of the solutions existence should be provided.

A modular structure of solution the complex M\&R management problem is illustrated in Fig. 2. Each structural unit (module) provides certain functions and its implementation is based on the modern software solutions. For example, module 1 - "Initial information" (database) is a set of circuit-mode data of power system (topology, elements parameters, and data of power consumption in the load nodes). It also includes a list of power equipment operational characteristics and results of diagnostic. In addition, module contains event information about power system emergency and scheduled outages. Thus information is used for determining the probabilistic characteristics of failures and recoveries of power equipment. Module 2 - "Goals and scenarios" is designed to set the priority objectives of the M\&R management and implementation scenarios. The following objectives (scenarios) are considered:

1. Reducing the probability of power equipment failure (improving the reliability);

2. Improving the operational reliability of equipment; 


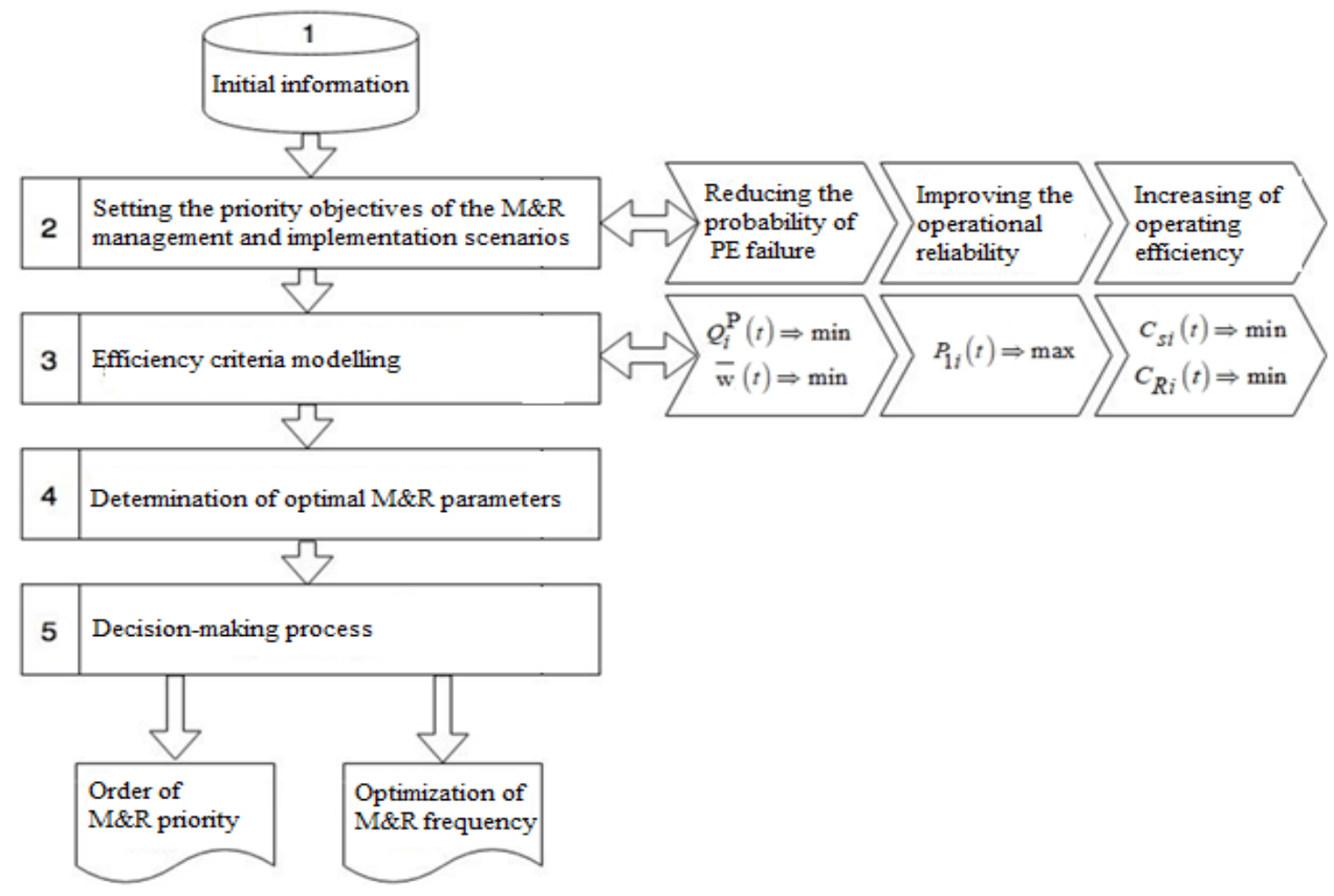

Fig. 2. Modular structure of solution the complex M\&R management problem of the distribution network equipment

3. Increasing of operating efficiency (reducing costs and damage).

Module 3 - "Efficiency Criteria" contains a set of criteria described in previous section D. Criterions modeling is based on the obtained equations (5) - (9).

Module 4 - "Optimization calculations" allows to rank the list of power equipment on the M\&R priority and to determine the optimal frequency of $M \& R$ on the considered operating time interval $\Delta \mathrm{t}$ for each unit of equipment according to the condition based strategy. The main module component is an algorithm of numerical calculation of equation system (4) and determination the optimal values of economic and reliability indexes (5) (9). Module 5 - "Decision-making process" provides the final expert evaluation of the obtained alternatives and selects the most preferred of them for implementation according to the established criterion of effectiveness.

The proposed solution module structure has a number of features that allows using this methodology for practical implementation. One of these features is the modular principle of construction, which allows increasing a number of solved problems. Another feature is an analytical form of the developed probabilistic models for the calculation of reliability and economic indexes of power equipment operation. It provides an opportunity to form decision-making areas on $M \& R$ parameters and investigate the impact on them a number of significant operational factors.

\section{Simulation results}

The implementation of developed methodology is considered on the real distribution power network 6-35 $\mathrm{kV}$. This power system is used for supplying oil-refined consumers. The network circuit has a tree structure (Fig. 3 ). The network power source is a two-transformer substation $35 / 6 \mathrm{kV}$. Each section of considered network includes overhead transmission lines (OHL) $6 \mathrm{kV}$ and PT $6 / 0.4 \mathrm{kV}$. Load sources are connected to the power transformers $6 / 0,4 \mathrm{kV}$, located on the multiple well platforms connected to the PS $35 / 6 \mathrm{kV}$ by the four not partitioned feeders of overhead lines (OHL) $6 \mathrm{kV}$ with multiple branches. Single-circuit $6 \mathrm{kV}$ OHL are made of AC-95/16 wire. In Table I given the individual characteristics and criteria for the ranking of overhead lines on the priority of the output in the repair, calculated on the developed models taking into account the aging factor in the operating interval $\Delta t=1$ year.

For calculations has been considered the presence of automatic load transfer (ALT) on the bus sections $0.4 \mathrm{kV}$ of all PT with duration of a current-free pause 0.003 hours. Failure of i-th OHL leads to interruption of power supply, disruption of the oil-refined process and losses $\Delta \overline{\bar{\Pi}}$. In case of failure the $6 \mathrm{kV}$ overhead lines (Table I) the value of technological loses $\Delta \bar{\Pi}$ is determined from equation (12):

$$
\Delta \bar{\Pi}=\bar{P}_{\text {load }} \cdot \bar{D} \cdot \Delta t_{\mathrm{ALT}}
$$




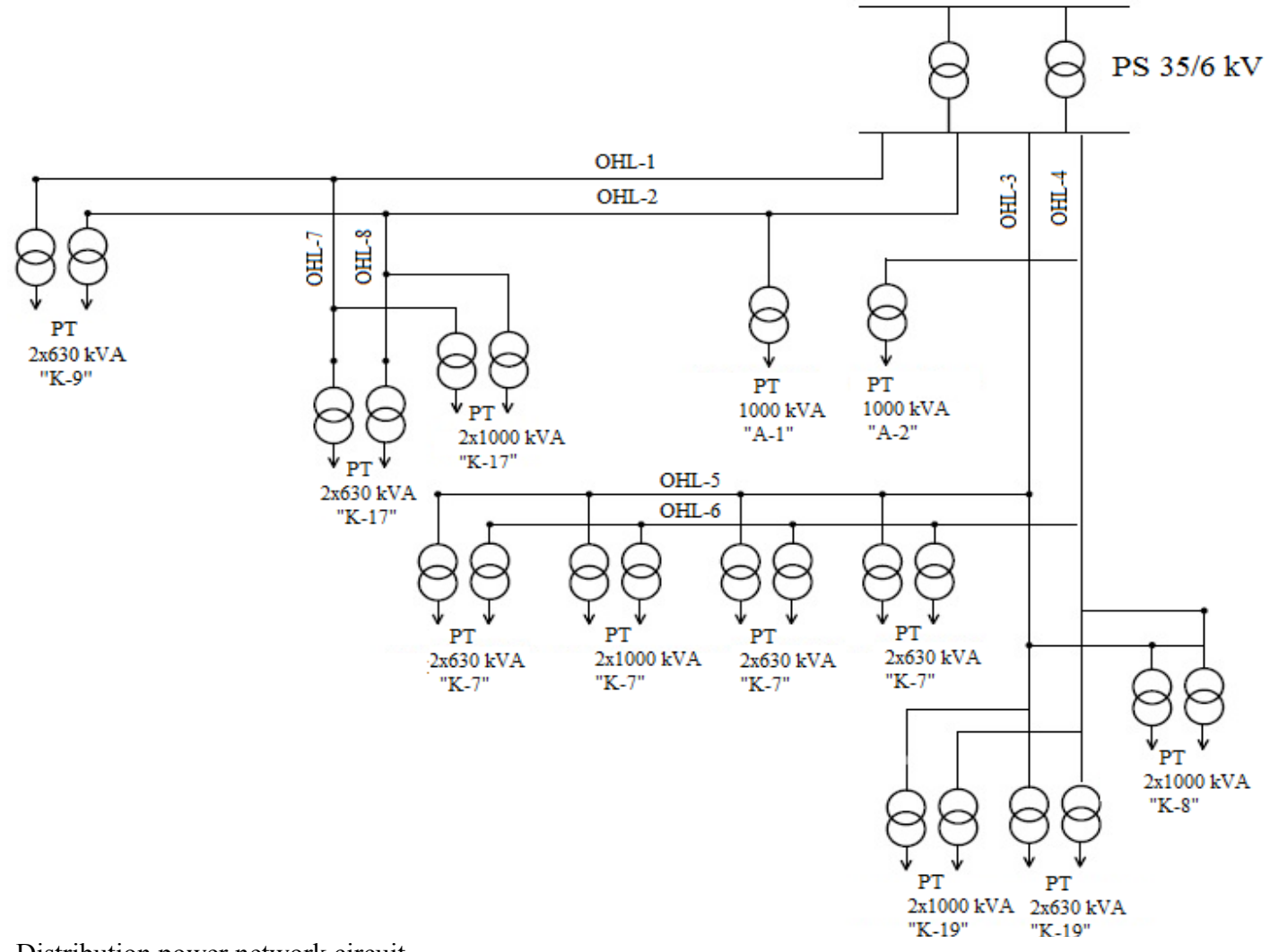

Fig. 3. Distribution power network circuit

where $\bar{P}_{\text {load }}$ - average active power of the PT load connected to the OHL, $\bar{D}-$ the average specific yield of wells, $\Delta t_{\mathrm{ALT}}$ - the duration of power supply interruption. The average loss frequency is assumed to be equal to $\lambda_{\Delta \Pi_{\mathrm{i}}}=0.125$ in accordance with the results of special statistical studies [16].

Table 2 shows the prioritized lists of order the M\&R procedures of $6 \mathrm{kV}$ overhead lines, arranged in accordance with different criteria of efficiency. The results of prioritizing reflect the significant impact of the individual factors on the order of M\&R procedures. For example, prioritizing the M\&R of OHL according to the criterion of minimum probability of failure, the most affect on obtained results provide the operation time (lifetime) parameter $t_{0}$. This parameter shows how long the considered object is under operational mode. In case of prioritizing the M\&R of OHL according to the criterion of minimum the average frequency of failures $\bar{w}_{\text {fail }}(t)$, including the condition-based M\&R strategy, the most influence parameter is length of OHL.

Prioritized list of M\&R procedures for OHL according to the criterion $\operatorname{Min} R_{\mathrm{cr}}$ is particularly the same with the order list criterion Min $Q$. This emphasizes the familiar properties of these proposed criteria. However, the impact of damage from technological losses of oil production has significant influence on the obtained results of $M \& R$ prioritizing. It takes the most importance in case of the failure of OHL3. This determines the highest priority of OHL-3 in the prioritized list. Similar calculations are carried out for UTS (unitized transformer substation) $6 / 0,4 \mathrm{kV}$ are given in Table 3.
Table 1. Calculated and operational parameters of OHL

\begin{tabular}{|c|c|c|c|c|c|c|c|c|}
\hline & L-1 & L-2 & L-3 & L-4 & L-5 & L-6 & L-7 & L-8 \\
\hline $\mathrm{L}, \mathrm{km}$ & 6,8 & 6,9 & 9,8 & $\begin{array}{c}10 \\
1\end{array}$ & 4,9 & 5,3 & 1,6 & 1,4 \\
\hline $\begin{array}{l}t_{0} \\
\text { year }\end{array}$ & 12 & 10 & 7 & 4 & 1 & 5 & 3 & 8 \\
\hline $\begin{array}{l}\omega_{0}, \\
1 / \text { yea } \\
\mathrm{r} \cdot \mathrm{km}\end{array}$ & \multicolumn{8}{|c|}{0,044} \\
\hline $\begin{array}{l}b, \\
\text { year-2 }^{-2}\end{array}$ & \multicolumn{8}{|c|}{0,005} \\
\hline $\begin{array}{l}\Delta \bar{\Pi}, \\
\text { ton/hr }\end{array}$ & 8,12 & 8,98 & $\begin{array}{c}18, \\
2\end{array}$ & $\begin{array}{c}15 \\
9\end{array}$ & $\begin{array}{c}8,8 \\
4\end{array}$ & $\begin{array}{c}10 \\
1\end{array}$ & $\begin{array}{c}5,5 \\
9\end{array}$ & $\begin{array}{c}6,2 \\
3\end{array}$ \\
\hline $\operatorname{Min} \bar{w}_{\mathrm{f}}$ & $\begin{array}{c}0,37 \\
9\end{array}$ & $\begin{array}{c}0,38 \\
5\end{array}$ & $\begin{array}{c}0,5 \\
4\end{array}$ & $\begin{array}{c}0,5 \\
6\end{array}$ & $\begin{array}{c}0,2 \\
8\end{array}$ & $\begin{array}{c}0,2 \\
9\end{array}$ & $\begin{array}{c}0,0 \\
9\end{array}$ & $\begin{array}{c}0,0 \\
8\end{array}$ \\
\hline$Q$ & $\begin{array}{c}0,30 \\
4 \\
\end{array}$ & $\begin{array}{c}0,29 \\
9\end{array}$ & $\begin{array}{c}0,3 \\
7 \\
\end{array}$ & $\begin{array}{c}0,3 \\
7\end{array}$ & 0,2 & $\begin{array}{c}0,2 \\
3 \\
\end{array}$ & $\begin{array}{c}0,0 \\
8\end{array}$ & $\begin{array}{c}0,0 \\
9\end{array}$ \\
\hline$R_{\mathrm{cr}}$ & $\begin{array}{c}0,16 \\
2\end{array}$ & $\begin{array}{c}0,17 \\
4\end{array}$ & $\begin{array}{c}0,5 \\
0\end{array}$ & $\begin{array}{c}0,4 \\
8\end{array}$ & $\begin{array}{c}0,0 \\
8\end{array}$ & $\begin{array}{c}0,1 \\
2\end{array}$ & $\begin{array}{c}0,0 \\
1\end{array}$ & $\begin{array}{c}0,0 \\
1\end{array}$ \\
\hline
\end{tabular}

Table 2. Results of prioritizing the M\&R procedures for OHL $6 \mathrm{kV}$

\begin{tabular}{|l|c|c|c|c|c|c|c|c|}
\hline \multirow{2}{*}{ Criterion } & L-1 & L-2 & L-3 & L-4 & L-5 & L-6 & L-7 & L-8 \\
\cline { 2 - 9 } & \multicolumn{6}{|c|}{ Prioritizing the order of M\&R procedures } \\
\hline Min $Q$ & 3 & 4 & 1 & 2 & 6 & 5 & 8 & 7 \\
\hline Min $\bar{w}_{\text {fail }}$ & 4 & 3 & 2 & 1 & 6 & 5 & 7 & 8 \\
\hline Min $R_{\text {cr }}$ & 4 & 3 & 1 & 2 & 6 & 5 & 8 & 7 \\
\hline
\end{tabular}

Table 4 shows the results of prioritizing the order of M\&R procedures for $\mathrm{PT} 6 / 0,4 \mathrm{kV}$ according to the various efficiency criteria. According to the criteria MinQ and Min $\bar{w}_{\text {fail }}$ is possible to prioritize the order of repairs for unitized (package) two-transformer 
Table 3. PT operational and reliability parameters

\begin{tabular}{|c|c|c|c|c|c|c|c|c|c|}
\hline $\begin{array}{c}\text { Well } \\
\text { platform }\end{array}$ & $\begin{array}{c}\text { Number } \\
\text { of PT }\end{array}$ & $\begin{array}{c}\text { Pload } \\
\mathbf{k W}\end{array}$ & $\begin{array}{c}\Delta \Pi \\
\text { ton } / \mathbf{h r}\end{array}$ & $\begin{array}{c}\text { to } \\
\text { (year) }\end{array}$ & $\begin{array}{c}\text { wo } \\
\left(\text { year }^{-1}\right)\end{array}$ & $\begin{array}{c}\text { b } \\
\left(\text { year }^{-2}\right)\end{array}$ & $\mathbf{Q}$ & $\begin{array}{c}\text { wfail } \\
\left(\text { year }^{-1}\right)\end{array}$ & Rer \\
\hline \multirow{2}{*}{ К9 } & 1 & 281 & 2,53 & \multirow{2}{*}{18} & \multirow{2}{*}{0,032} & \multirow{2}{*}{0,004} & \multirow{2}{*}{0,4857} & \multirow{2}{*}{0,0528} & 0,7016 \\
\hline & 2 & 279 & 2,75 & & & & & & 0,7938 \\
\hline \multirow{4}{*}{ K17 } & 1 & 309,7 & 1,58 & \multirow{2}{*}{10} & \multirow{2}{*}{0,025} & \multirow{2}{*}{0,002} & \multirow{2}{*}{0,4055} & \multirow{2}{*}{0,0402} & 0,0973 \\
\hline & 2 & 310,1 & 2,83 & & & & & & 0,2417 \\
\hline & 3 & 581,3 & 4,01 & \multirow{2}{*}{2} & \multirow{2}{*}{0,018} & \multirow{2}{*}{0,001} & \multirow{2}{*}{0,2636} & \multirow{2}{*}{0,0286} & 0,0781 \\
\hline & 4 & 575,1 & 3,4 & & & & & & 0,0625 \\
\hline \multirow{2}{*}{ A } & 1 & 325,5 & - & 16 & 0,024 & 0,002 & 0,3624 & \multirow{2}{*}{0,0387} & 0,0512 \\
\hline & 2 & 412,2 & - & 4 & 0,018 & 0,001 & 0,1647 & & 0,0662 \\
\hline \multirow{8}{*}{ К7 } & 1 & 309,7 & 1,63 & \multirow{2}{*}{6} & \multirow{2}{*}{0,02} & \multirow{2}{*}{0,002} & \multirow{2}{*}{0,3495} & \multirow{2}{*}{0,0326} & 0,823 \\
\hline & 2 & 307,2 & 1,91 & & & & & & 1,3471 \\
\hline & 3 & 536,4 & 3,64 & \multirow{2}{*}{16} & \multirow{2}{*}{0,025} & \multirow{2}{*}{0,004} & \multirow{2}{*}{0,4883} & \multirow{2}{*}{0,0422} & 1,3053 \\
\hline & 4 & 581,1 & 5,36 & & & & & & 0,7124 \\
\hline & 5 & 394,4 & 2,58 & \multirow{2}{*}{22} & \multirow{2}{*}{0,035} & \multirow{2}{*}{0,005} & & 00583 & 0,0317 \\
\hline & 6 & 384,2 & 1,75 & & & & 0,5893 & 0,0583 & 0,0375 \\
\hline & 7 & 337,9 & 1 & & & & & & 2,3943 \\
\hline & 8 & 325,3 & 1,1 & 8 & 0,022 & 0,002 & 0,3812 & 0,0357 & 0,9602 \\
\hline & 1 & 670,5 & 4,2 & 20 & 0038 & 0005 & 053 & 00629 & 0,0979 \\
\hline 10 & 2 & 665,3 & 2,21 & 20 & 0,038 & 0,005 & 0,53 & 0,0629 & 0,0552 \\
\hline K19 & 3 & 394,2 & 2,54 & 13 & 2020 & 0 & 01075 & 00365 & 0,0928 \\
\hline & 4 & 366,9 & 1,76 & 13 & 0,022 & 0,002 & $0,19 / 5$ & 0,0365 & 0,0502 \\
\hline K8 & 1 & 670,5 & 2,61 & & & & & & 0,7016 \\
\hline K8 & 2 & 715,2 & 1,76 & 12 & 0,03 & 0,001 & 0,1563 & 0,0467 & 0,7938 \\
\hline
\end{tabular}

substations (Fig.3) in general, the criterion Min $R_{\text {cr }}$ allows rank the order of M\&R for each power transformer separately. This feature of $\operatorname{Min} R_{\mathrm{cr}}$ criterion

improves the $M \& R$ management and reduces risk of failure. According to the MinQ criterion, the highest priority belongs to the UTS 5, 6 (well platform K-7) with the most aged equipment $\left(t_{0}=22\right.$ years). Criterion Min $\bar{w}_{\text {fail }}$ sets the highest priority for UTS 1, 2 (well platform K-19) with the highest values of the initial failure rate $\omega_{0}$ and equipment ageing rate $b$.

Criterion Min $R_{\text {cr }}$ establishes the highest priority of M\&R procedures for the PT $6 / 0.4 \mathrm{kV}$ with the highest value of damage in case of interruption the oil production process due to emergency failure of PT. From the point of severity of consequences, the PT failure, the five most important power transformers (parts of UTS) are placed in well platform K-7, which has the highest well capacity (Table 4).

To determine the optimal frequency of $M \& R$ procedures $\left(T_{\mathrm{opt}}\right)$ for each service object provides the following computational procedure:

1. Input initial data;

2. Setting the initial value of parameter $t_{i}=t_{0}$;

3. Solution the system of equations (4) using Gauss method;

4. Verification of one of the conditions $\frac{d P_{1}(t)}{d t}=$ $0, \frac{d \bar{w}_{\text {fail }}}{d t}=0, \frac{d C_{\mathrm{R}}(t)}{d t}=0 ;$

5. The fulfillment of the condition (paragraph 4) means that desired solution is obtained $t_{i}=T_{\text {opt }}$;

6. In case of breach the condition (paragraph 4) determines new value of parameter $\mathrm{t} t_{i+1}=t_{i}+\Delta t$;
7. Start again from paragraph 3 still desired solution will not obtained.

Table 4. Results of prioritizing the order of $M \& R$ procedures for PT $6 / 0.4 \mathrm{kV}$

\begin{tabular}{|c|c|c|c|c|}
\hline \multirow{2}{*}{$\begin{array}{l}\text { Well } \\
\text { platforms }\end{array}$} & \multirow{2}{*}{$\begin{array}{l}\text { Number } \\
\text { of PT }\end{array}$} & \multicolumn{3}{|c|}{ Prioritizing criteria } \\
\hline & & $\operatorname{Min} Q$ & $\operatorname{Min} \bar{w}_{\text {fail }}$ & $\operatorname{Min} R_{\mathrm{cr}}$ \\
\hline \multirow{2}{*}{ К-9 } & 1 & \multirow{2}{*}{4} & \multirow{2}{*}{3} & 7 \\
\hline & 2 & & & 6 \\
\hline \multirow{4}{*}{ К-17 } & 1 & \multirow{2}{*}{9} & \multirow{2}{*}{6} & 11 \\
\hline & 2 & & & 9 \\
\hline & 3 & \multirow{2}{*}{5} & \multirow{2}{*}{11} & 13 \\
\hline & 4 & & & 15 \\
\hline \multirow{2}{*}{ A } & 1 & \multirow{2}{*}{7} & \multirow{2}{*}{7} & 17 \\
\hline & 2 & & & 14 \\
\hline \multirow{8}{*}{ K-7 } & 1 & \multirow{2}{*}{8} & \multirow{2}{*}{10} & 5 \\
\hline & 2 & & & 2 \\
\hline & 3 & \multirow{2}{*}{3} & \multirow{2}{*}{5} & 3 \\
\hline & 4 & & & 8 \\
\hline & 5 & \multirow{2}{*}{1} & \multirow{2}{*}{2} & 20 \\
\hline & 6 & & & 19 \\
\hline & 7 & \multirow{2}{*}{6} & \multirow{2}{*}{9} & 1 \\
\hline & 8 & & & 4 \\
\hline \multirow{4}{*}{ K-19 } & 1 & \multirow{2}{*}{2} & \multirow{2}{*}{1} & 10 \\
\hline & 2 & & & 16 \\
\hline & 3 & \multirow{2}{*}{10} & \multirow{2}{*}{8} & 12 \\
\hline & 4 & & & 18 \\
\hline \multirow{2}{*}{ К-8 } & 1 & \multirow{2}{*}{11} & \multirow{2}{*}{4} & 7 \\
\hline & 2 & & & 6 \\
\hline
\end{tabular}

Fig. 4 illustrates the solution according to proposed technique for $\bar{w}_{\text {fail }}(t)$ and $C_{\mathrm{R}}(t)$ characteristics. 
In Table 5 the results of calculations $T_{\mathrm{opt}}$ in accordance with the criterion Min $\bar{w}_{\text {fail }}(t)$ for UTS 6/0.4 $\mathrm{kV}$ are summarized. The obtained values of the optimal M\&R periodicity include the individual characteristics of the operated equipment, as well as various initial failure rates. Obtained results are varying in the range from 1.72 to 3.14 years, which is consistent with the real operating conditions.

Table 5. Values of optimal M\&R periodicity of UTS $6 / 0.4 \mathrm{kV}$

\begin{tabular}{|c|c|c|c|c|c|c|c|c|}
\hline К9 & K17 & $\mathbf{A}$ & & 77 & & & 19 & K8 \\
\hline \multicolumn{9}{|c|}{$T_{\text {opt }}$, (year) } \\
\hline 1,9 & 2,3 & 2,3 & 1,7 & 1,8 & 2,1 & 1,9 & 2,1 & 3,1 \\
\hline
\end{tabular}

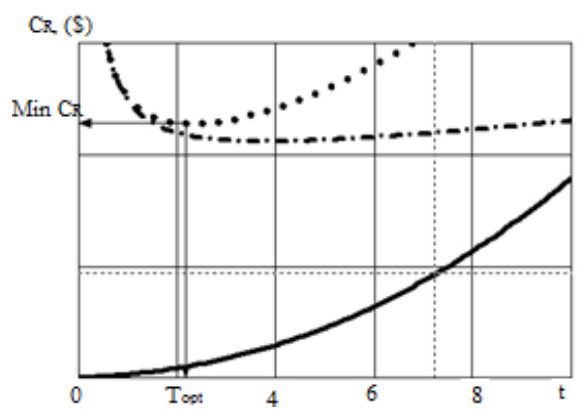

a) $\operatorname{Min} \stackrel{4}{R}_{R}(t)$ criterion

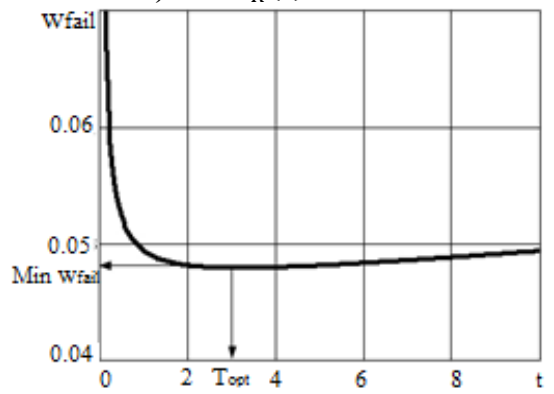

b) Min $\bar{w}_{\text {fail }}(t)$ criterion

Fig. 4. Determination of M\&R optimal time for PT $6 / 0.4 \mathrm{kV}$

Figures 4a) and 4b) demonstrate monotonous changes in these reliability and economic indexes, and also the presence of function extremum ( $\mathrm{min} / \mathrm{max}$ value) on the considered time. It determines the possibility of using the considered dependencies as target functions for optimizing the frequency of equipment repair.

\section{Conclusions}

An effective methodology for management of maintenance and repair of power network equipment has been developed. The proposed strategy is based on the theory of random controlled Markov (semi-Markov) processes with continuous time. The developed methodology is a set of theoretical and instrumental tools. It includes methods of collection and processing of emergency and diagnostic statistics data, probabilistic mathematical models, obtained for calculation and optimization of operational reliability indexes and condition-based M\&R parameters of the power network equipment.

Practical application of the developed methodology allows solve complex problem maintenance and repair management and provide efficient operation of power network equipment. It could be achieved by increasing the failure-free operation probability, minimizing failures consequences and cost savings from the implementation of M\&R procedures.

The complex solution of M\&R management problem using proposed methodology is provided on the part of real oil-refined distribution power network. According to the obtained results, it is possible to prioritize the order of M\&R procedures for overhead transmission lines 6 $\mathrm{kV}$ and power transformers (UTS) $6 / 0,4 \mathrm{kV}$ in terms of variation the considered management criteria.

The proposed methodology allows to calculate the optimal values of the $M \& R$ management parameter for power equipment and ensure the efficiency of the operation strategy over a given time interval.

This paper presents calculated values of the optimal time interval for the next scheduled maintenance for each power transformer $6 / 0.4 \mathrm{kV}$ of considered part of the electrical power system

The developed methodology has been recommended for implementation in distribution network of oil fields, where the application of these efficiency criteria is relevant and there is a homogeneous composition of power energy consumers.

\section{References}

1. E. B Dynkin, Controlled Markov processes and their applications (Science, Moscow, 1975).

2. V. S. Korolyuk, Semi-Markov processes and their applications (Naukova Dumka, 1976).

3. V. M. Levin and D. V. Tanfileva, Nauch. West. The NSTU, 2, 135-146 (2011).

4. V. M. Levin, E. A. Rychagova, I. V. Sorokin, Proceedings International Science Conference Issues of Technical Sciences (2015).

5. V. M. Levin, E.A. Rychagova, Proceedings International Conference on Probabilistic Methods Applied to Power Systems (PMAPS) (2016).

6. E. Rychagova, 47 Session CIGRE (2018).

7. E. Shayeteh and P.Hilber, Proceedings International Conference on Probabilistic Methods Applied to Power Systems (PMAPS) (2016).

8. C.Moldoveanu, V. Brezoianu, A.Vasile, V. Ursanu, S.Gal, V.Metiu, C.Diaconu and VI.Rosca, 44 Sessions CIGRE (2012).

9. J. Endrenyi, IEEE Transactions, 16, 638-644 (2001).

10. Final Project Report, PSERC Publication (2003).

11. E.J. Barzilovich, Models maintenance of complex systems: Proc. allowance (Higher School, Moscow, 1982).

12. I. Gertsbakh, Theory of Reliability with Applications to Preventive Maintenance (Springer-Verlag, 2000).

13. I. B. Gersbach, Kh. B. Kordonskiy, Failure Models (Soviet radio, Moscow, 1966). 
14. V. M. Levin, Proceedings International Science Conference Modern power systems and complexes, and their management, (2008).

15. E. S. Ventzel, Probability Theory (Nauka, Moscow, 1969).

16. V.M. Levin, Chief Power Engineer, 1., 61-68, (2013). 